\title{
Design, Producing and Testing of 12-Step Three-Phase Voltage Source Inverter with Flexible Independent PWM Current Control for Brushless Direct Current Motor
}

\section{Mehmet Cihat ÖZGENEL ${ }^{1 *}$}

\begin{abstract}
Brushless motors are used in wide areas in the industrial and domestic applications owing to their superior advantages over other type electric motors such as induction and brushed direct current motors. Owing to fact that the brushless direct current motors and their drivers are cheaper and easier to design than drives of permanent magnet synchronous motors, brushless direct current motors are preferred a large application areas. But BLDC motor drivers are still run classical three-phase sixstep inverter. Because of that the BLDC motors are run classical three-phase six-step inverter, the BLDC motor does not show its real dynamic performance. If BLDC motor is run via 12-step inverter, it gives a better dynamic performance than that of six-step inverter. The aim of this study, to manufacture 12-step inverter which controls phase currents using pulse width modulation (PWM) technique and to analyze the dynamic performance of BLDC motor running under purposed 12-step inverter. In the 12-step inverter, two or three transistors are on conduction mode at each time interval alternatively and in order to keep switching losses minimum only one transistor runs PWM mode in this study. The experimental results show that purposed flexible independent PWM 12-step inverter works perfectly and this proposed inverter provides the BLDC motor generating high dynamic performance than that of six-step one.
\end{abstract}

Keywords: BLDC Motor, voltage source inverter, 12-step inverter, six-step inverter, PWM current control, BLDC motor speed control.

\footnotetext{
1 Mehmet Cihat ÖZGENEL (Orcid ID: 0000-0001-5304-1488), Erzincan Binali Yildirim University, Faculty of Engineering, Department of Electrical Electronics Engineering, Erzincan, Turkey

*Sorumlu Yazar/Corresponding Author: Mehmet Cihat ÖZGENEL, e-mail: mcozgenel@erzincan.edu.tr

The article was presented as a summary in the International Academic Research Congress on 30 October-03 November 2018 in Alanya / Antalya
}

Geliş tarihi / Received: 19-09-2019

Kabul tarihi / Accepted: 28-12-2019 


\section{INTRODUCTION}

As it is well known that some electric motors run from power supply directly such as induction, brushed small power DC motors and universal motors, but some of electric motors need drivers to run such as PMSM, BLDC motor and stepper motors. If the induction motors, brushed small power DC motors and universal motors are used applications requires variable speed or torque control, these motors must also be used with the drivers. In other words, if speed and torque control is required, all electric motors need drivers. These drivers are often referred to as inverters. Inverters are power electronics circuits that convert direct current to alternating current. They are used in numerous applications such as switching power supplies in electronics devices, motor drivers and DC high voltage transportation (Mangroliya et al., 2013; Shah et al., 2013). Furthermore inverters are used in solar and wind energy systems. In generally inverters are used a large number of variable frequency drives for AC motor control (Saied et al., 2006; Mahsewari et al., 2015). AC motors are largely induction motors, synchronous motors universal motors and brushless motors. These motors require a driver not only running but also controlling speed and torque control of motor. Among the AC motors, it is seen that the brushless motors have superior features. Brushless motors are used in wide areas in the industrial and domestic applications owing to their superior advantages over other type electric motors such as induction and brushed direct current motors. Some advantages of brushless motors are; they have small size compared to AC motors for the same power, good linear torque-speed characteristic, easy torque and speed control, noiseless operating, high efficiency, fast dynamic response (Ozgenel, 2017).

Brushless motors are divided into two main groups according to the shape of the back electromotive force in the phase windings. The first one is trapezoidal back electro motive force in the phase winding that is called brushless direct current motor and the second one is sinusoidal back electro motive force in the phase winding that is called permanent magnet synchronous motor (PMSM). While permanent magnet synchronous motors phase windings are fed by sinusoidal current, permanent magnet direct current motors phase windings are fed by trapezoidal currents via three-phase inverter (Ozgenel, 2017). Both PMSM and BLDC motors are need rotor position information to be made commutation properly. In order to feed to PMSM phase windings with sinusoidal current, rotor position of PMSM is sensed by sinusoidal encoder, incremental encoder or resolver with high accuracy which is relatively expensive. Since BLDC motor windings are fed with trapezoidal current, BLDC motor rotor position is sensed roughly with 60-electrical degree interval by Hall-effect magnetic sensors which are low cost. Because of that the BLDC motors are run classical three-phase six-step inverter, the BLDC motor does not show its dynamic potential performance. In six-step BLDC motor drives, only any two phases of three phase-windings are active and one phase winding is inactive at a step of six-step (Ahmed, 2015). The empty phase does not contribute to the production speed and torque (Ozgenel, 2018). In the BLDC motor, which uses a six-step inverter, the utilization rate of the phase windings is 66 percent (ST Microelectronics, 2006; Ozgenel, 2018). In order to get higher performance from the same BLDC motor, it is necessary to increase the duration of the current passing through the phase windings of the BLDC motor. This is easily achieved by employing 12-step inverter. If the BLDC motor runs with a 12-step inverter, it will produce more torque and speed than the BLDC motor runs in the 6-step inverter. Because in the 12-step inverter three phases are active at the same time and contribute to the torque and speed production, BLDC motor generates more speed and torque. The rate of utilization of phase winding is 83 percent in BLDC motor which works with 12 step inverter (Ozgenel, 2018). 
In this study, both six-step and twelve-step inverter with independent PWM current control are designed and manufactured in order to compare effect on the BLDC motor performance. Flexible independent PWM current control scheme is used in 12-step inverter.

\section{MATERIALS AND METHODS}

\section{Driving Of Bldc Motors}

Figure 1 is depicted a conventional BLDC motor driver system. A typical BLDC driver system is consist of rotor position sensors, inverter, commutation logic circuitry, inverter transistor driver and BLDC motor. Commutation logic circuitry generates transistor gate signals according to rotor position and adjusts PWM duty cycle according to speed demand. When the rotor rotates, position sensors (SA $\mathrm{SB}$ and SC) generate logic 1 and logic 0 . This rotor position information is used to energize motor phase windings via power transistors. Inverter converts DC voltage into rectangular alternate voltage for BLDC motor phase windings. Thus, BLDC motor runs and position signals are changed with the changing rotor position and commutation is made at the each 60 -electrical degree. While commutation is done automatically in brushed DC motors with the help of collector and brushes but it is done electronically in BLDC motors. Commutation is the change of direction of current passing through motor phase windings according to rotor position.

In brushless AC motors, the rotor position information must be detected by a position sensor in order to energize phase windings according to rotor position. This position sensor is generally Halleffect magnetic sensor in BLDC motors (Ozgenel, 2017). Hall-effect sensors are placed on the stator by 120 -electrical degree apart from each other. The rotor position is detected by Hall-effect sensors by 60 -electrical degree interval. Rotor position information is used to commutate BLDC motor phase windings. Owing to fact that the rotor position is detected every 60 -electrical degree, one electrical period occurs in six-step. Thus design of six-step inverter is easy and less complicated. Numerous commercial manufacturers are produced chips dedicated six-step BLDC motor driver (Ohm and Oleksuk, 2002). BLDC motors are currently being operated with 6-step inverters. As it is seen easily from Table 1, in six-step driver, two transistors are conduction mode and one phase winding is connected to positive terminal of DC source and one phase winding is connected to negative terminal of DC source at each step.

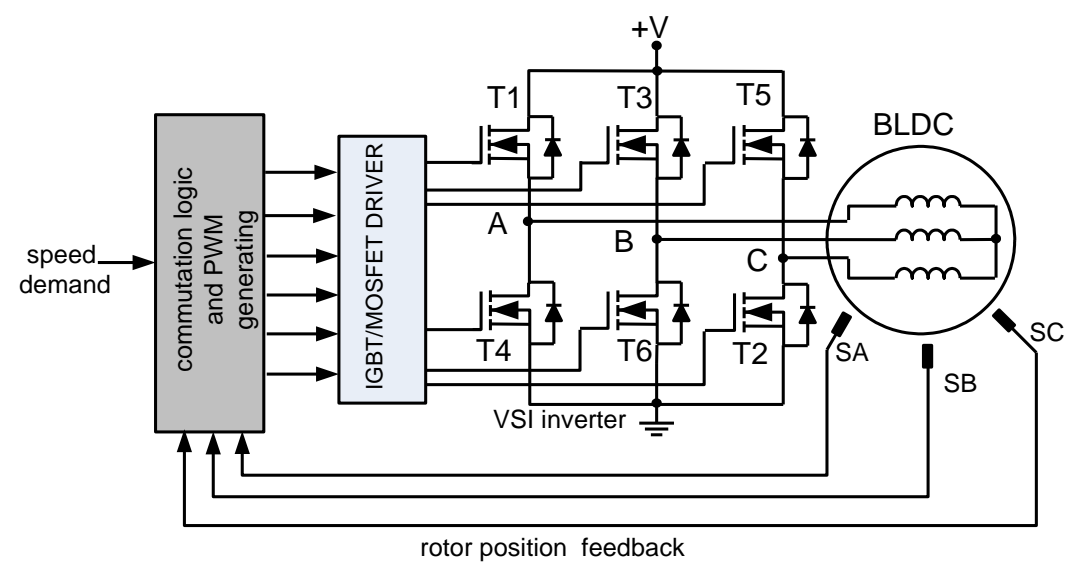

Figure 1. Typical six-step BLDC motor driving system 
After six-step is completed, it is returned to first step. So, one period is completed. If Table 1 is examined, two-phase winding is energized at each step and pair of phase windings is changed at each step, each step is 60 electrical degrees. On Table 1 in the first step, A-phase winding is connected to positive terminal of DC source and C-phase winding is connected negative terminal of DC source. In this step A and C-phase windings produces torque and velocity. In the second step, while $\mathrm{C}$ - phase is still connected to negative terminal of DC source, C-phase winding is changed its pair of phase winding from A-phase to B-phase.

Table 1. Status of inverter transistors, energized phase windings according to rotor position switches in six-step inverter

\begin{tabular}{|c|c|c|c|c|c|c|c|c|c|c|}
\hline \multirow[t]{2}{*}{ Step } & \multicolumn{6}{|c|}{ Status of inverter transistors } & \multirow{2}{*}{$\begin{array}{l}\text { Energized } \\
\text { phase } \\
\text { windings }\end{array}$} & \multicolumn{3}{|c|}{ Position swithes } \\
\hline & $\mathrm{T} 2$ & T5 & T6 & T3 & T4 & T1 & & SA & $\mathrm{SB}$ & $\mathrm{SC}$ \\
\hline 1 & On & Off & FREE & FREE & Off & On & $\mathrm{A}+, \mathrm{C}-$ & 1 & 0 & 0 \\
\hline 2 & On & Off & Off & On & FREE & FREE & $\mathrm{B}+, \mathrm{C}-$ & 1 & 1 & 0 \\
\hline 3 & FREE & FREE & Off & On & On & Off & $\mathrm{B}+, \mathrm{A}-$ & 0 & 1 & 0 \\
\hline 4 & Off & On & FREE & FREE & On & Off & $\mathrm{C}+, \mathrm{A}-$ & 0 & 1 & 1 \\
\hline 5 & Off & On & On & Off & FREE & FRE & $\mathrm{C}+, \mathrm{B}-$ & 0 & 0 & 1 \\
\hline 6 & FREE & FREE & On & Off & Off & On & $\mathrm{A}+, \mathrm{B}-$ & 1 & 0 & 1 \\
\hline
\end{tabular}

In the third step, his time B-phase winding is the same, A-phase is replaced by C-phase. The sixstep inverter operation continues in this way. Due to fact that two phase's windings should be energized at each step in six-step inverter, and then two switches should conduct at any step (Chen et al., 2009). As it is known well, due to fact that pulse width modulation technique reduces power losses and having greater efficiency in the system is commonly used in DC-DC converters and motor speed control applications (Bolloju, 2007). The output voltage can be easily changed by adjusted conduct time of power switch. The average voltage of PWM DC-DC convertor is expressed;

$V_{o}=V_{D C} \frac{t_{o n}}{T}$

Where, $V_{o}$ is the PWM converter output voltage, $V_{D C}$ is the input voltage, $t_{o n}$ is conduct time of power transistor and $T$ is the period of PWM frequency.

\section{Speed Control of Bldc Motor}

Because the speed of the BLDC motor depends on the amplitude of the voltage applied to the phase windings, the speed control of the BLDC motor is implemented by changing the amplitude of the voltage applied to the phase windings as it is in direct current motors with brushed (Varghese et al., 2014). The amplitude of the voltage applied to the phase windings can be easily changed using the pulse width modulation technique (PWM). PWM voltage control scheme is the most used speed control technique for BLDC motors (Pindoriya et al., 2014). In PWM technique, the amplitude of the phase voltage is adjusted by changing the duration of the pulse using power transistors in inverter. There are two main ways of power transistor switching schemes in the inverter with PWM signals: independent and complementary modes (Breji et al., 2006). In the independent PWM mode, inverter upper (T1, T3 and T5) or lower (T4, T6 and T2) transistors are run in PWM mode. This mode is relatively simple to control BLDC motor phase voltage. In the complementary mode, the power transistors in one phase inverter leg for example $\mathrm{T} 1$ and $\mathrm{T} 4$ are run complementary. Implementation of this scheme is relatively complex according to independent PWM mode. In six-step inverter, two phase windings are energized and one phase winding is free all time intervals. While two phase windings generate torque and speed but one phase winding does not contribute generating torque and speed. Each phase winding 
is energized with other phase winding is free during one step interval which is equal to 60 electrical degrees in six-step inverter. Each step interval is 60 electrical degrees. So, commutation occurs at each 60 electrical degrees.

\section{Six-step voltage source inverter with pwm phase voltage control}

The independent mode PWM voltage control method is used in six-step inverter. Many commercial integrated circuit manufacturers produce independent PWM controlled BLDC motor predriver integrated such as MC33033, LV8127T from ON Semiconductor corp., DRV8302 from Texas Instruments corp., FCM8201 from Fairchild Semiconductor corp. is a BLDC motor inverter pre-driver which uses complementary PWM scheme. In this proposed inverter, PWM signals are generated by employing SG3526 high performance pulse width modulator integrated circuit from ON Semiconductor corp. (On Semiconductor Corp., 2006). The PWM frequency is selected $20 \mathrm{kHz}$. To obtain the output of phase voltage of six step inverter, equation (2) should use (Promthong and Konghirun, 2013);

$V_{\text {phase }(120)}=0.41 V_{D C}$

Where $V_{D C}$ is the input DC voltage of inverter from DC supply. Equation (2) is valid when duty cycle of PWM 100\%. If duty cycle of PWM smaller than 100\%, the following equation is used;

$V_{\text {phase }(120)}=0.41 V_{D C} \frac{t_{\text {on }}}{T}$

From Figure 2, it is seen that every time interval only two phase windings are energized. While one phase winding is connected positive terminal of DC supply, other phase is connected to negative terminal of DC power supply. One phase winding is free. During one period, one phase winding is continuously non-energized. This non-energized winding is changed at each step. While in step 1, Bphase winding is free (non-energized), in step 2, A-phase winding is non-energized and so on. Thus only two phase windings are produced torque and speed in six-step BLDC motor drivers. Since the speed of BLDC motor is proportional to phase winding voltage the BLDC speed is changed by changing phase voltage using PWM technique. In Figure 2, PWM scheme is applied to T4, T6 and T2 transistors which are connected to negative terminal of DC power supply.

A twelve-step PWM voltage controlled voltage source inverter is designed and implemented. To avoid using numerous logic gates, quite cheap and useful Arduino-Nano platform which is based Atmega328 microchip is used. Table 2 is taken into consideration when designing this inverter. In twelve-step inverter, one electrical period is completed at 12 steps. In order to accomplish the 12-step inverter, rotor position should be sensed each 30-electrical degree (Babaei and Mahaei, 2011; Promthong, 2013; Shah et al., 2013). As it is seen from Table 2, while three phase windings are active on one step, two phase windings are active in next step. When three phase windings are active, three power transistors in inverter are at conduction mode, when two phase windings are active two transistors are at the conduction mode. While three transistors are in conduction mode in one step, two transistors are in conduction mode in the next step. Switching of the power transistors continues in this way. The output voltage of twelve-step inverter is expressed as following (Babaei and Mahaei, 2011; Promthong, 2013);

$V_{\text {phase(150) }}=0.44 V_{D C}$ 
Equation (4) is valid when duty cycle of PWM 100\%. If duty cycle of PWM smaller than 100\%, the following equation is used;

$$
V_{\text {phase }(150)}=0.44 V_{D C} \frac{t_{\text {on }}}{T}
$$

Equations (4 and 5) show that twelve-step inverter produces higher phase voltage than that of six-step inverter. This means BLDC motor running in twelve-step inverter produces more speed than BLDC motor which runs in six-step inverter because BLDC motor speed is proportional is directly phase voltage.
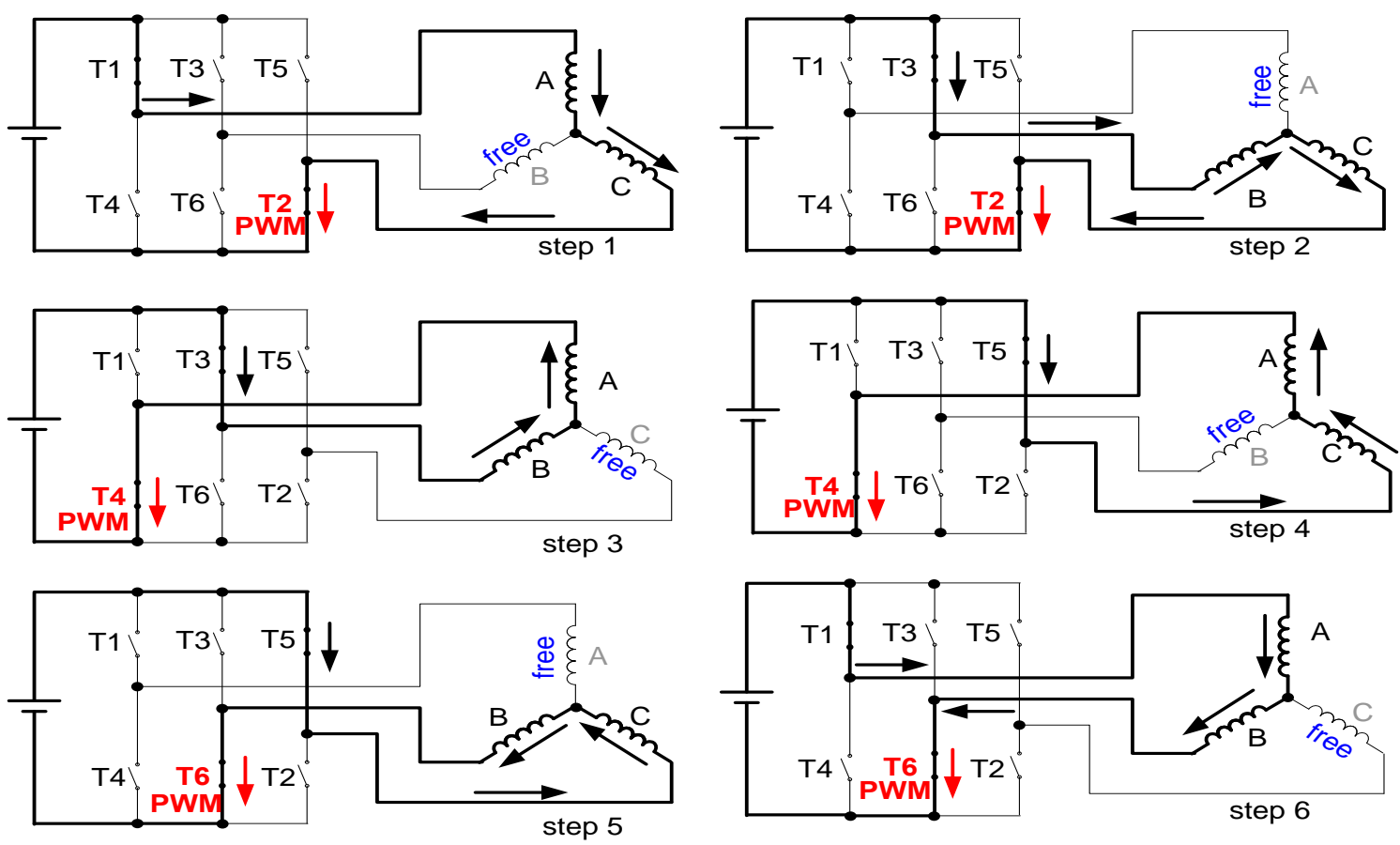

Figure 2. Commutation sequence in six-step inverter

Table 2. Status of inverter transistors, energized phase windings and PWM mode transistors in twelve-step inverter

\begin{tabular}{|c|c|c|c|c|c|c|c|c|}
\hline \multirow[t]{2}{*}{ Step } & \multicolumn{6}{|c|}{ Status of inverter transistors } & \multirow{2}{*}{$\begin{array}{l}\text { Energized } \\
\text { phase } \\
\text { windings }\end{array}$} & \multirow{2}{*}{$\begin{array}{c}\text { Transistors operating in PWM } \\
\text { mode }\end{array}$} \\
\hline & $\mathrm{T} 2$ & T5 & T6 & T3 & T4 & T1 & & \\
\hline 1 & Off & On & On & Off & Off & On & $\mathrm{A}+, \mathrm{C}+, \mathrm{B}-$ & T6 \\
\hline 2 & FREE & FREE & On & Off & Off & On & $\mathrm{A}+, \mathrm{B}-$ & T6 \\
\hline 3 & On & Off & On & Off & Off & On & $\mathrm{A}+, \mathrm{B}-, \mathrm{C}-$ & T1 \\
\hline 4 & On & Off & FREE & FREE & Off & On & $\mathrm{A}+, \mathrm{C}-$ & T1 \\
\hline 5 & On & Off & Off & On & Off & On & $\mathrm{A}+, \mathrm{B}+\mathrm{C}-$ & T2 \\
\hline 6 & On & Off & Off & On & FREE & FREE & $\mathrm{B}+, \mathrm{C}-$ & $\mathrm{T} 2$ \\
\hline 7 & On & Off & Off & On & On & Off & $\mathrm{A}-, \mathrm{B}+, \mathrm{C}-$ & T3 \\
\hline 8 & FREE & FREE & Off & On & On & Off & $\mathrm{A}-, \mathrm{B}+$ & T3 \\
\hline 9 & Off & On & Off & On & On & Off & $\mathrm{A}-, \mathrm{B}+, \mathrm{C}+$ & T4 \\
\hline 10 & Off & On & FREE & FREE & On & Off & $\mathrm{A}-, \mathrm{C}+$ & T4 \\
\hline 11 & Off & On & On & Off & On & Off & A-, B-, C+ & T5 \\
\hline 12 & Off & On & On & Off & FREE & FREE & B-, C+ & T5 \\
\hline
\end{tabular}


In twelve-step inverter, from Table 2, while three transistors are on conduction mode in the first step (T1, T6 and T5) and A-phase and C-phase are connected to positive terminal of DC power source but B-phase is connected to negative terminal of DC power source. In this step, since the sum of the currents coming from the phases A and C pass over the B phase, so T6 transistor should run on PWM mode. T1 and T5 transistors are kept full conduction mode in this step. Since each step is 30 degrees, each transistor is on PWM mode during 60 electrical degrees during a period. In step 2, A-phase winding is connected positive terminal of DC power supply B-phase winding is connected to negative terminal of DC power supply. In this step T6 transistor is still PWM mode. In the third step, the polarity of phases A and B remain the same while the polarity of phase $\mathrm{C}$ is changed. The polarity of phase $\mathrm{C}$ is changed from first step to third step.

In this step, PWM transistor is changed, now T1 transistor is on PWM mode. In the fourth step, the polarity of phases A and C remain the same, the current of phase B is cut. In the fifth step, the direction of B phase current is changed. Transistor T1 is on PWM mode in the third and fourth step. In the fifth step, A-phase and C-phase remain the same, the current direction of B-phase is changed and transistor T2 runs on PWM mode. So, three-phase windings are used generating torque and velocity in twelve step inverter and BLDC motor shows better performance. Twelve-step control scheme, the inverter operation continues in this way. In this mode inverter, independent PWM control scheme is used in order to reduce switching losses. In Table 2, each transistor is conduction mode during five steps which is equal 150 electrical degrees. But each transistor is on PWM mode during two steps (60 electrical degrees) and each transistor operates in full mode in the remaining 90 degrees. To ensure this mode of operation, a circuit has been designed to produce required gate signals as shown in Figure 4 (a) and (b). In this gate signal generating circuit, two gate signals are generated for one transistor. These two gate signals are combined in an OR gate. In Table 2, transistor T1 is on conduction mode (full mode) in step 1 and step 2, this time full mode output of commutation logic circuitry is active for step 1 and step 2. In the same time the PWM output of commutation logic circuitry is inactive and 4066 bilateral switch is open. So, transistor T1 is full conduction mode. Third and fourth steps, transistor T1 runs PWM mode this time the PWM output of commutation logic circuitry is active and 4066 bilateral switch is closed and the PWM signal is connected to OR gate but this time full mode output of commutation logic circuitry is inactive for step 3 and step 4. Thus, transistor T1 runs PWM mode on steps 3 and 4 . When the fifth step is reached, full mode output of commutation logic circuitry is active and the PWM output of commutation logic circuitry is inactive and 4066 bilateral switch returns to open state. Thus, transistor T1 is runs full conduction mode for 30 electrical degrees.

At the end of the fifth step, transistor T1 is completed five steps and 150 degrees. After transistor T1 is completed five steps, it keeps off state during five steps and it is free mode in steps 6 and 12 . Other transistors in inverter run the same way. Thus, on each step, one transistor runs PWM mode and for PWM operation only one transistor is employed. Thus, each transistor in the inverter is operated in PWM mode for 60 degrees and a flexible 12-step PWM controlled drive is obtained. On the other hand, since one transistor is used in each step for PWM, the switching losses are minimized. 

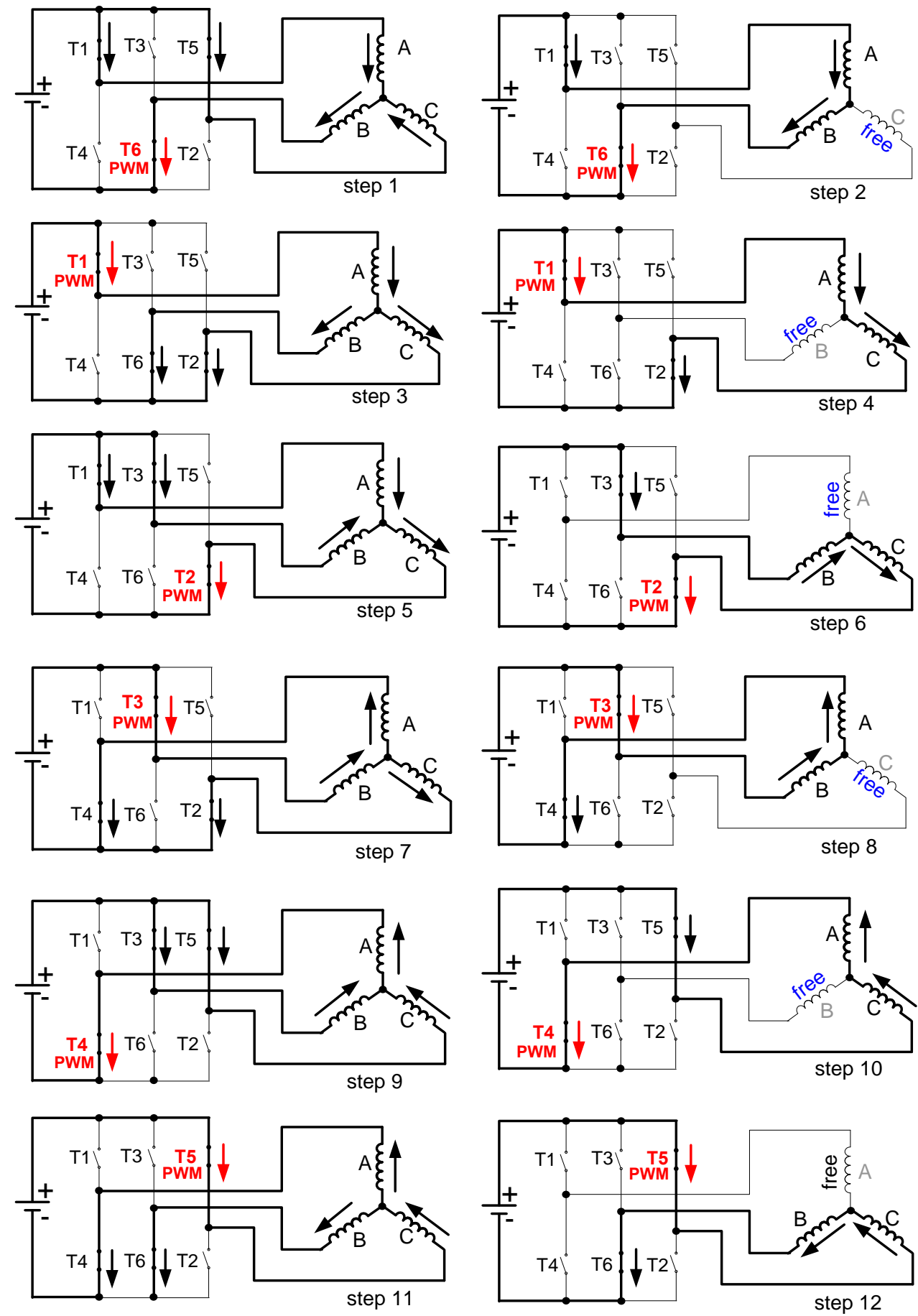

Figure 3. Status of transistors and energized of phase windings in twelve-step inverter

\section{Experimental procedure}

In addition to designed and manufactured six-step and twelve-step PWM controlled inverter, it is also a BLDC motor experimental setup up has been manufactured for this experimental study (Figure 5). Thus, the effect of both six-step and twelve-step PWM controlled inverter on the performance of BLDC motor has been tested. BLDC motor has been run PWM controlled six-step and twelve-step step inverters. PWM frequency is set up $20 \mathrm{kHz}$ and one period is $50 \mu \mathrm{s}$. 


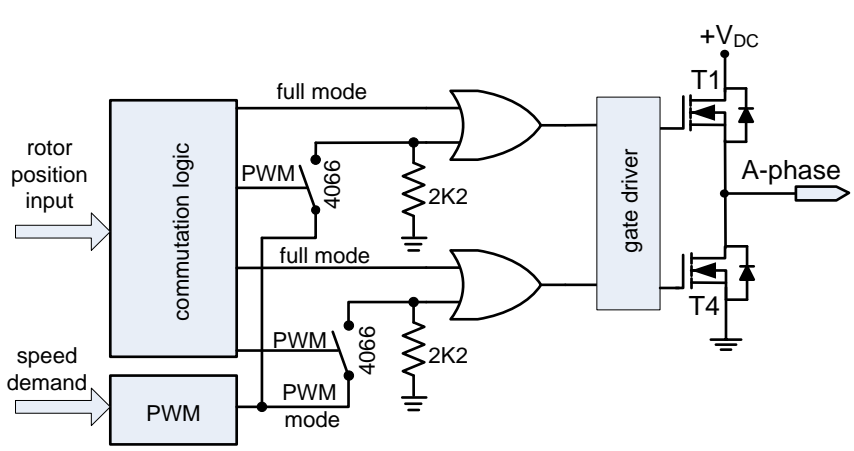

(a)

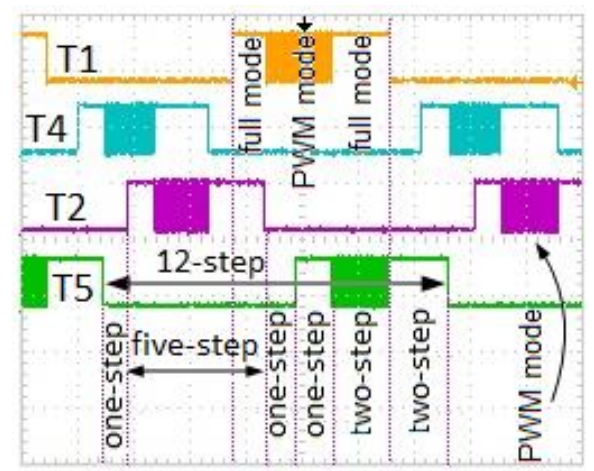

(b)

Figure 4. Generating one phase transistors gate signals in proposed twelve-step inverter (a), structure of gate signals of A and $\mathrm{B}$ phases transistors (b)

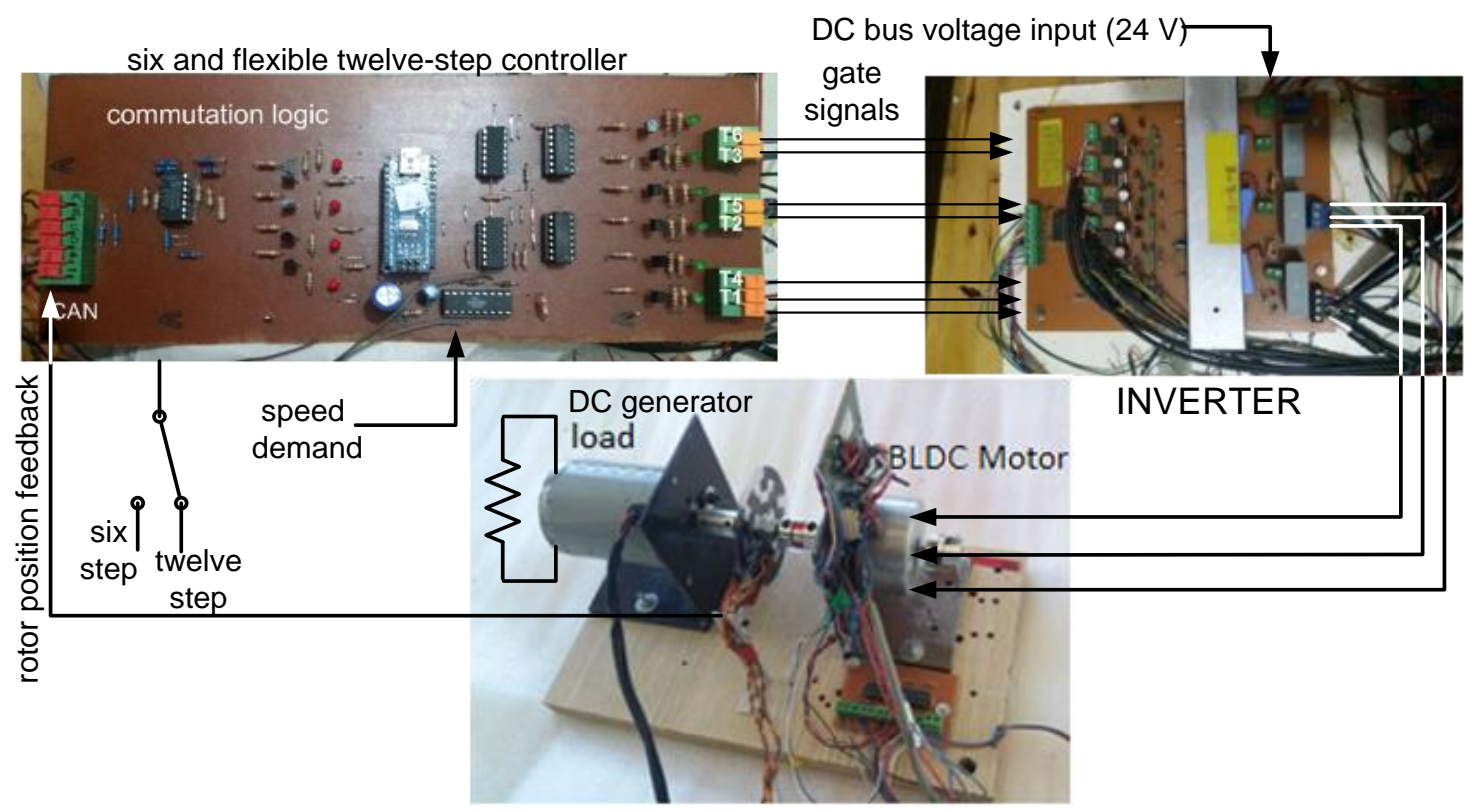

Figure 5. Purposed twelve-step inverter and experimental setup

Duty cycle of PWM is set up to $21 \mu \mathrm{s}, 32 \mu \mathrm{s}$ and $40 \mu \mathrm{s}$ for both six-step and twelve-step inverters. BLDC motor has been run for these duty cycles of PWM and motor performance is examined. During experiments motor load is kept constant. A permanent magnet DC generator is used as a BLDC motor load and 2.6 $\Omega$ resistive load is connected to DC generator as generator load. While motor speed, motor current and phase voltage have been measured but motor power and torque have been calculated using motor speed, phase current and back electromotive force (EMF). Thus, the effect of both six and twelve-step PWM controlled inverter on the BLDC motor performance can be brought into the open.

Table 3. BLDC Motor Parameters

\begin{tabular}{cccccc}
\hline Brand & $\begin{array}{c}\text { Rated Voltage } \\
(\mathrm{V})\end{array}$ & $\begin{array}{c}\text { Rated torque } \\
(\mathbf{m N m})\end{array}$ & $\begin{array}{c}\text { Rated speed } \\
(\mathbf{r p m})\end{array}$ & $\begin{array}{c}\text { Rated current } \\
(\mathbf{A})\end{array}$ & $\begin{array}{c}\text { Back EMF constant } \\
(\mathbf{V} / \mathbf{k r p m})\end{array}$ \\
\hline Shinano Kenshi & 24 & 160 & 1800 & 2.1 & 2.54 \\
\hline
\end{tabular}




\section{RESULTS AND DISCUSSION}

Six-step and twelve-step PWM current controlled voltage controlled inverter (VSI's) have been run and tested. It was checked whether both inverters work as in theory. It is clearly seen in Figure 6(a) that independent PWM mode works perfectly for six-step inverter. In six-step independent PWM voltage controlled inverter, each transistor is conduction mode during two-step (120-degree). In independent mode, transistor T1 which is connected to positive terminal of DC power supply works full conduction mode. For negative pulse of motor current, transistor T4 is conduction mode for full time (120-degree). In Figure 6(b), the gate signals of switching transistors in twelve-step inverter are shown. In Figure 6(b), it is seen that gate signals are observed to be in perfect accordance with the Table 2. As it is shown in Figure 6(b), each transistor is on full conduction mode the first 30-degree (one step) then each transistor runs on PWM mode during 60-degree (two-step), after transistor working on PWM mode, the transistor returns to full conduction mode for 60-degree (two-step). So one transistor is on conduction mode during five steps, two steps of these are PWM mode and other three modes are full conduction mode. From the tests as shown in Figure 6(b), it is clearly seen the PWM controlled 12-step inverter intended for this study has been found to work perfectly. BLDC motor has been run under the same load by employing six and twelve-step inverter by adjusting PWM duty cycle various times.

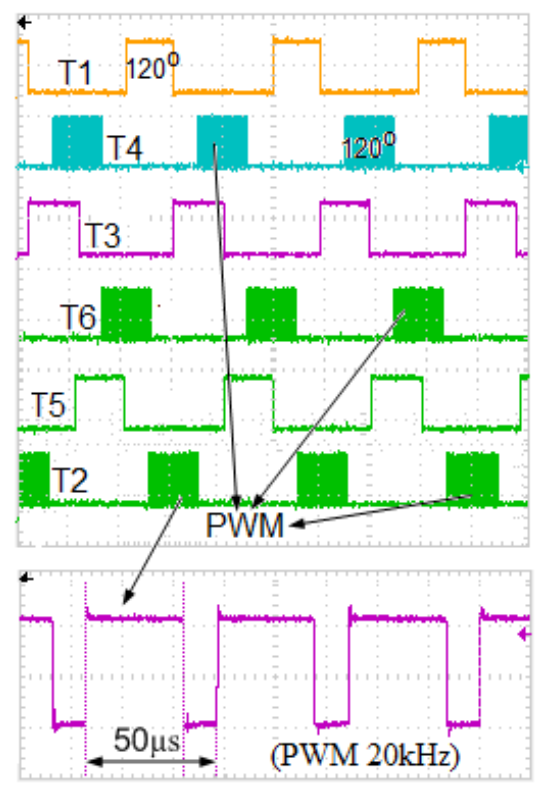

(a)

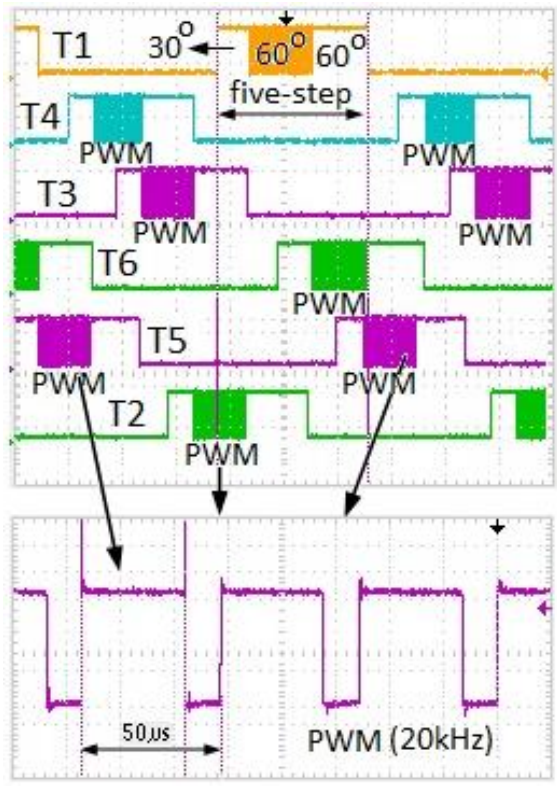

(b)

Figure 6. PWM waveforms; (a) six-step, (b) purposed twelve-step inverter

These duty cycles are $21 \mu \mathrm{s}, 32 \mu \mathrm{s}$, and $40 \mu \mathrm{s}$. So, the effects of both inverters on BLDC motor performance have been easily found out. Table 4 shows that power, torque and speed response of BLDC motor according to five different duty cycles. As seen from Table 4, When BLDC motor works in twelve-step inverter, BLDC motor generates more speed, power and torque than that of working on six-step inverter under same load and for the same duty cycle. It is clearly seen that from the Table 4, while duty cycle is $21 \mu \mathrm{s}$, The BLDC motor generates $122 \mathrm{mNm}$ torque in six-step inverter and BLDC motor generates $174 \mathrm{mNm}$ for the same duty cycle in twelve-step inverter, it is also seen from Table 4 for the $21 \mu \mathrm{s}$, BLDC motor generates $42 \%$ more torque while working on twelve-step inverter than 
that of six-step one. In other duty cycles, the BLDC motor has also produced more power, speed and torque in proposed flexible PWM controlled 12-step inverter than that of six-step one. When the BLDC motor has been run for various duty cycles on six and twelve-step inverters, power and torque generated by the BLDC motor has been calculated following expressions respectively (Ozgenel, 2018);

$P_{\text {shaft }}=E_{a} \cdot I_{a}+E_{b} \cdot I_{b}+E_{c}+I_{c}$

$T_{e}=\frac{P_{\text {shaft }}}{\omega_{r}}=\frac{E_{a} \cdot I_{a}+E_{b} \cdot I_{b}+E_{c} \cdot I_{c}}{\omega_{r}}$

Where $E_{x}$ is the back electromotive force of the corresponding phase in Volt, $I_{x}$ is the relevant phase current in Ampere and $\omega_{r}$ is the angular velocity in $\mathrm{rad} / \mathrm{s}$.

The following equation has been used to determine the effects of the six and proposed 12-step PWM controlled inverter on the torque generated by the BLDC motor (Ozgenel, 2018);

$\Delta T_{e}=\frac{T_{e(12)}-T_{e(6)}}{T_{e(6)}}$

Where $T_{e(12)}$ and $T_{e(6)}$ are the torques that are generated by BLDC motor when working on 12 and 6step PWM controlled inverter in $\mathrm{Nm}$ and $\Delta T$ is the ratio of the effect of the 12-step inverter and the 6step inverter on the motor torque.

Table 4. Performance of BLDC motor working on six and proposed twelve-step inverter according to various duty cycles

\begin{tabular}{cccccccccc}
\hline $\begin{array}{l}\text { Duty cycle } \\
(\mu \mathrm{s})\end{array}$ & $\begin{array}{c}\text { Phase current } \\
(\mathrm{A})\end{array}$ & $\begin{array}{c}\text { Speed } \\
(\mathrm{rpm})\end{array}$ & $\begin{array}{c}\text { Shaft Power } \\
(\mathrm{W})\end{array}$ & $\begin{array}{c}\text { Torque } \\
(\mathrm{mNm})\end{array}$ & $\begin{array}{c}\text { Phase current } \\
(\mathrm{A})\end{array}$ & $\begin{array}{c}\text { Speed } \\
(\mathrm{rpm})\end{array}$ & $\begin{array}{c}\text { Shaft Power } \\
(\mathrm{W})\end{array}$ & $\begin{array}{c}\text { Torque } \\
(\mathrm{mNm})\end{array}$ & $\begin{array}{c}\Delta \mathrm{T} \\
\%\end{array}$ \\
\hline 21 & 1.5 & 826 & 10.63 & 122 & 1.96 & 970.8 & 17.72 & 174 & 42 \\
\hline 32 & 2.19 & 1234 & 22 & 170 & 2.68 & 1470 & 32.54 & 211 & 24 \\
\hline 40 & 2.67 & 1515 & 32.7 & 206 & 3.14 & 1724 & 44.19 & 244 & 18 \\
\hline
\end{tabular}

BLDC motor has been run on both six and twelve-step PWM controlled inverters and motor speed and motor phase current measured then motor power and motor torque have been calculated by yielding equations (6) and (7). After motor torque and power have been calculated, the effect of both six and twelve-step inverters on motor torque is calculated using equation (8). These values are given in Table 4.In this study, BLDC motor dynamic performance is also tested for both inverters. Figure 7(a) shows that speed response of BLDC motor according to two inverter schemes. When BLDC motor starts up with six-step inverter, the rotor speed reaches $1305 \mathrm{rpm}$ within 750 milliseconds while duty cycle is $64 \%$ (32 $\mu \mathrm{s})$. Although the duty cycle remains the same in 32 microseconds, BLDC motor speed reaches $1538 \mathrm{rpm}$ in the same time (750 milliseconds) when BLDC motor runs with 12-step inverter (Figure 7(a)). Thus, Figure 7(a) shows that BLDC motor running with 12-step inverter speed response is faster than that of six-step.

In Figure 7(b) duty cycle is reduced from $32 \mu \mathrm{s}$ to $29 \mu \mathrm{s}$ in order to obtain the same speed response. It is obviously seen from Figure 7(b) that BLDC motor working with 12-step inverter gives the same speed response less duty cycle time $(29 \mu \mathrm{s})$. Figure 7 proves that the proposed 12-step scheme gives BLDC motor better dynamic response. Inverter phase voltages have been also calculated and measured in order to examine the performance of generating phase voltage of proposed 12-step inverter. 


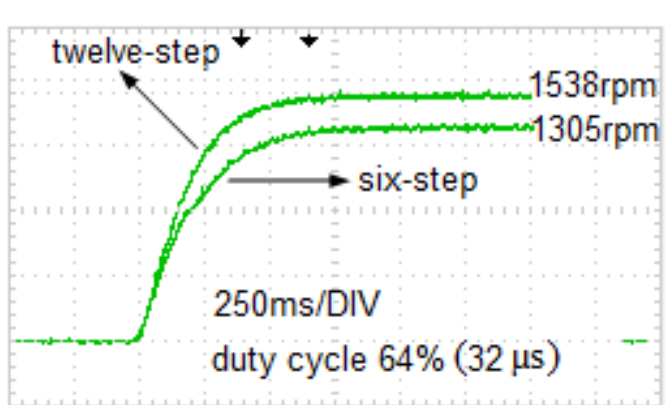

(a)

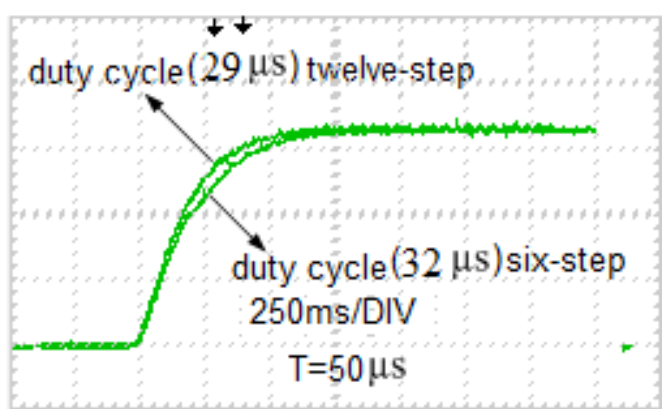

(b)

Figure 7. Start up of BLDC motor when duty cycle $64 \%$ (32 $\mu \mathrm{s})$ for both inverters (a), reducing the duty cycle from $32 \mu \mathrm{s}$ to $29 \mu$ s to obtain the same dynamic performance in 12 -step inverter (b)

Table 5. Phase voltages according to duty cycles for both inverters

\begin{tabular}{ccccc|cr}
\hline \multirow{2}{*}{$\begin{array}{c}\text { DC bus Voltage } \\
(\mathbf{V})\end{array}$} & $\begin{array}{c}\text { Duty cycle } \\
(\mathbf{5})\end{array}$ & $\begin{array}{c}\text { Transistor } \\
\text { conduction time }(\boldsymbol{\mu s})\end{array}$ & \multicolumn{4}{c}{ Phase voltages(V) } \\
\cline { 4 - 7 } & & & Six-step inverter & \multicolumn{2}{c}{ Twelve-step inverter } \\
\hline 24 & 42 & 21 & 4.02 & 4.05 & calculated & measured \\
\hline 24 & 64 & 32 & 6.14 & 5.85 & 6.43 & 4.33 \\
\hline 24 & 80 & 40 & 7.68 & 7.27 & 8.44 & 6.63 \\
\hline
\end{tabular}

Table 5 shows that proposed flexible PWM 12-step inverter produces phase voltage in accordance with the equation (5). Calculated phase voltages and measured phase voltages are very close to each other. The BLDC motor phase currents are also recorded.

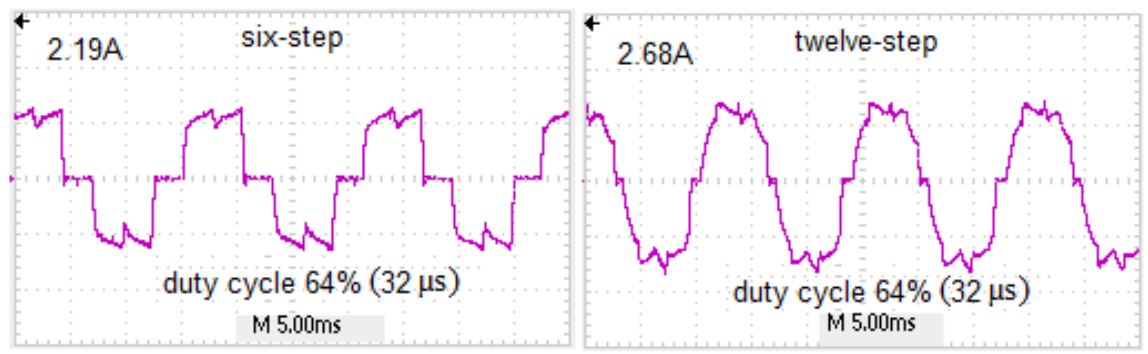

(a)

(b)

Figure 8. Phase currents of BLDC motor on both six and proposed 12-step drivers

Figure 8 shows that one phase currents when the duty cycle is $32 \mu \mathrm{s}$. In Figure 8(a) while BLDC motor phase current is a typical six-step inverter phase current, 12-step inverter phase current is closely sinusoidal current. Sinusoidal phase current ensures to BLDC motor some advantages such as smooth operation, less torque ripple, fewer harmonic (Mahsewari et al., 2015). PWM frequency $20 \mathrm{kHz}$ has been selected in this study since many inverter pre-driver chip producers use $20 \mathrm{kHz}$ PWM frequency. Thus one period is $50 \mu \mathrm{s}$.

\section{CONCLUSIONS}

Proposed flexible PWM controlled 12-step voltage source inverter intended for this study has been found to work perfectly as it is seen from Figure 6(b). It is seen that Figure 6(b) is fully compatible with the Table 2. This experimental study shows that BLDC motor gives satisfactorily dynamic response when BLDC motor employing on purposed twelve-step flexible PWM controlled 
inverter as it is shown in Table 4 and Figure 7. In Table 4, when duty cycle is 21 microseconds, the BLDC motor running in twelve-step inverter has generated more $42 \%$ torque than that of running in six-step inverter. For each duty cycle, BLDC motor has generated more torque, power and speed. As duty cycle increases, the difference between the torques decreases. When duty cycle is 40 microsecond, the difference between of torques becomes $18 \%$. When duty cycle is 32 microseconds, in this time, phase current is $2.68 \mathrm{~A}$ in 12 -step inverter, the difference between of torques is $24 \%$. The proposed flexible 12-step inverter allows the BLDC motor to generate more torque, power and speed. Figure 7 shows that BLDC motor reaches to $1538 \mathrm{rpm}$ when it runs with proposed inverter but it reaches to $1305 \mathrm{rpm}$ within the same time $(750 \mathrm{~ms})$. Thus the BLDC motor running with proposed inverter shows fast dynamic response. Furthermore, the proposed inverter controller provides that the BLDC motor phase currents are very close to sinusoidal current. Sinusoidal phase currents have some advantages such as silent operation of the motor, less torque fluctuation and harmonics. BLDC motor speed control is done easily by proposed flexible 12-step inverter.Due to fact that proposed flexible twelve-step inverter provides the BLDC motor generating more torque, more power and fast dynamic response, 12-step PWM controlled inverter can be used in required high performance applications such as robotic, industrial automation applications, medical surgery, office machines, aerospace applications, drones, solar irrigation systems and portable devices.

\section{REFERENCES}

Ahmed MA, 2015. Brushless DC Motor Speed Control Using both PI Controller and Fuzzy PI Controller. International Journal of Computer Applications, 109 (10): 29-35.

Babaei E, Mahaei M, 2011. Improving Output Voltage of the Three Phase Six-Switch Inverters. Telkomnika, 9 (3): 497-502.

Bolloju V, 2007. PWM Control Methods Increases Efficiency, Reliability and Extend Battery Lifetime. Motion Application Center. International Rectifier, Bodo's Power Systems.

Breji M, Princ M, Sustek P, 2006. BLDC Motor with Hall Sensors and Speed Closed Loop, Driven by eTPU an MPC5554. Application Note, Freescale Semiconductor, AN3006, Rev. 1, 05/2006., Inc.: $1-41$.

Chen Hung-Chi, Huang Chih-Kai, Tsai Tzu-Yang, 2009. BDCM Sensorless Control for Twelve-Step Square-Wave PWM. International Conference on Power Electronics and Drive Systems (PEDS), 2-5 Nov. 2009, Taipei.

Maheswari MH, Gohil MV, Tahilramani M, 2015. Implementation of three phase 12-step VSI with harmonics reduction. International Journal of Advance Engineering and Research Development (IJAERD) 3: 1-6.

Mangroliya DG, Rupapara VJ, Akabari RP, Vaghela NM, 2013. An advanced three phase VSI with $150^{\circ}$ conduction mode using PIC 16F72. Journal of information, knowledge and research in electrical engineering. 2 (2): 352-357.

Ohm DY, Oleksuk RJ, 2002. Influence of PWM Schemes and Commutation Methods for DC and Brushless Motors and Drives. Drivetech, Inc. Northrop Grumman Poly-Scientific: 1-9.

ON Semiconductor Corp., 2006. SG3526 Pulse Width Modulation Control Circuit July 2006 Rev.4. Datasheet: 1-9.

Ozgenel MC, 2017. Design, implementation, and application of 150-degree commutation VSI to improve speed range of sensored BLDC motor. Review of Scientific Instruments 88: 095007-1095007-8, doi: 10.1063/1.4997613. 
Ozgenel MC, 2018. Increasing power and torque capability of brushless direct current motor by employing 150-degree conduction mode controlled three-phase voltage source inverter. Review of Scientific Instruments 89: 085002-1-085002-9. doi: 10.1063/1.5033957.

Pindoriya RM, Rajendran S, Priyesh C, 2014. Speed Control of BLDC Motor Using PWM Technique. International Journal of Advance Engineering and Research Development (IJAERED) ETCEE. $1-6$.

Promthong S, Konghirun M, 2013. Sensorless control of BLDC motor drive with $150^{0}$ conducting mode to minimize torque ripple. International Conference on Electrical Machine and Systems, Oct, 26-29, (ICEMS) Busan, Korea.

Saied MH, Mostafa MZ, Abdel-Moneim TM, Yousef H. A, 2006. On three-phase six-switch voltage source inverter: A $150^{\circ}$ conduction mode. In IEEE ISIE (IEEE, Montr'eal, Qu'ebec, Canada).

Shah A, Mangroliya D, and Vaghela N, 2013. Simulation and Analysis of an Advanced $150^{\circ}$ Conduction Mode for Three Phase Voltage Source Inverter. ACEEE, Proc. Of. Int. Conf. on Emerging Trends in Engineering and Technology.

ST Microelectronics, 2006. Low cost sinusoidal control of BLDC motors with Hall sensors using ST7FMC, AN2373 Application note: 1-13.

Varghese AJ, Roy R, Thirunavukkarasu S, 2014. Optimized Sped Control for BLDC Motor. International Journal of Innovative Research in Science, Engineering and Technology, 3 (1). 